\title{
THE MANAGEMENT OF SUBARACHNOID HAEMORRHAGE IN THE BRITISH ARMY
}

\author{
Lieutenant-Colonel P. J. BEALE, M.B., M.R.C.P., R.A.M.C. \\ British Military Hospital, Hannover
}

SUMMARY: Eight patients are presented with subarachnoid haemorrhage diagnosed in British Military Hospitals in West Germany. They fall into two groups, those having a spontaneous origin, and those arising as a result of trauma. The management of both groups is discussed with particular regard to early diagnosis and prompt evacuation of suitable patients to the United Kingdom.

\section{Introduction}

During the period of 18 months from December 1972 to June 1974, eight patients with subarachnoid haemorrhage $(\mathrm{SAH})$ were seen by the author in the British Military Hospitals at Münster and Hannover in West Germany. Spontaneous bleeding had occurred in five patients, four of whom had so-called 'berry' aneurysms and one a cerebral angiomatous malformation. Haemorrhage in the other three patients was attributed to trauma.

The eight cases are presented briefly in chronological order, and are summarised in Table I.

Table I

Final diagnosis and outcome of 8 patients with subarachnoid haemorrhage

\begin{tabular}{|c|c|c|c|c|}
\hline $\begin{array}{c}\text { Case } \\
\text { number }\end{array}$ & $\begin{array}{l}\text { Age } \\
\text { years }\end{array}$ & Sex & Diagnosis & Outcome \\
\hline 1 & 38 & $\mathrm{~F}$ & $\begin{array}{l}\text { ? Aneurysm basilar/posterior } \\
\text { cerebral artery }\end{array}$ & Died Day 5 \\
\hline 2 & 21 & $\mathrm{~F}$ & $\begin{array}{l}\text { Traumatic subarachnoid haemorrhage. } \\
\text { Hypoclycaemia }\end{array}$ & Living \\
\hline 3 & 26 & $\mathrm{~F}$ & Right anterior cerebral angioma & Living \\
\hline 4 & 23 & M & $\begin{array}{l}\text { Right posterior communicating } \\
\text { aneurysm }\end{array}$ & $\begin{array}{l}\text { Right common carotid } \\
\text { closure. Living }\end{array}$ \\
\hline 5 & 26 & M & $\begin{array}{l}\text { Traumatic subarachnoid haemorrhage. } \\
\text { Gastric crosions }\end{array}$ & Died Day 7 \\
\hline 6 & $9 / 12$ & $\mathrm{~F}$ & Traumatic subarachnoid haemorrhage & Living \\
\hline 7 & 42 & $\mathrm{~F}$ & $\begin{array}{l}\text { Right posterior communicating } \\
\text { aneurysm }\end{array}$ & $\begin{array}{l}\text { Craniotomy. Residual } \\
\text { deficit. Living }\end{array}$ \\
\hline 8 & 26 & M & $\begin{array}{l}\text { Left posterior communicating } \\
\text { aneurysm }\end{array}$ & Died Day 1 \\
\hline
\end{tabular}

\section{Patient 1}

\section{Case histories}

A woman aged 38 woke up one morning not feeling well, developed a headache and started to behave oddly. She soon lapsed into coma and was deeply unconscious with fixed pupils on arrival at the hospital. She was unable to breathe on her own. 
Other findings were of retinal haemorrhages, mild mitral incompetence and a blood pressure (B.P.) of 150/100. The cerebrospinal fluid contained 12,500 red blood corpuscles (RBCs) per $\mathrm{mm}^{3}$, and a protein content of $1,640 \mathrm{mg} / 100 \mathrm{ml}$. There was no xanthochromia. Skull X-ray was normal.

No lightening of her degree of coma occurred and she died 5 days after admission. Post mortem examination showed extensive subarachnoid haemorrhage at the base of the brain with subdural extension into the middle and anterior fossae. There was a distinct rupture of the arterial wall at the junction of the basilar artery with the posterior cerebral artery. On general examination only minimal atheroma was seen, and there was some thickening and scarring of the mitral valve without vegetations.

\section{Patient 2}

A 21 year old English housewife who was a known ' brittle diabetic' on twice daily soluble insulin. On leaving her flat one morning she fell down a flight of stairs hurting her head. She became unconscious and was admitted to a local German hospital where the blood sugar was found to be $37 \mathrm{mg} / 100 \mathrm{ml}$. She was given sugar. On transfer to the British Military Hospital, she showed signs of cerebral irritability, and a bruise over the left parietal region. There was mild neck rigidity. Her B.P. was 100/70. Skull X-ray revealed two linear fractures, one in the left parietal region and the other in the right occipital region. Lumbar puncture tapped blood-stained and xanthochromic fluid with $1900 \mathrm{RBC}$ 's per $\mathrm{mm}^{3}$ and a protein content of $172 \mathrm{mg} / 100 \mathrm{ml}$. Gradual but uneventful recovery occurred. Subsequently (Day 10) at the Neuro-Surgical Unit in the Brooke Hospital, Woolwich, it was decided that no further investigations were required and a diagnosis of traumatic subarachnoid haemorrhage was made. Hypoglycaemia may have played an important role in the history, either by causing her fall, or, in an insulindependent diabetic, resulting from starvation afterwards.

\section{Patient 3}

A 26 year old English schoolteacher complained of occipital headaches and vomiting for 24 hours. On admission to hospital she was mildly febrile but there was no meningism. B.P. was 140/70. Improvement was sufficient to consider discharge but two evenings later she was found disorientated, walking around a strange ward. She was becoming drowsy, and neck stiffness had now appeared.

The cerebrospinal fluid contained $8000 \mathrm{RBCs}$ per $\mathrm{mm}^{3}$ and a protein content of $45 \mathrm{mg} / 100 \mathrm{ml}$. Three days later, she was fully alert and had no complaints. On Day 6 she was evacuated to the Brooke Hospital, Woolwich, where angiography revealed a right sided cerebral angioma in the territory of the right anterior cerebral artery (Figs 1 and 2). Surgery was not recommended.

\section{Patient 4}

A 23 year old single Welsh Signaller who fainted whilst standing on parade. He was unconscious for less than a minute, but on recovery complained of a generalised headache and vomiting. He did however remember having had a severe but momentary headache two weeks previously, again accompanied by vomiting. Apart from a moderate degree of neck stiffness, he exhibited no other abnormal signs. His B.P. was 130/80. Lumbar puncture revealed fluid containing $500,000 \mathrm{RBCs}$ per $\mathrm{mm}^{3}$ with a protein content of $100 \mathrm{mg} / 100 \mathrm{ml}$. 

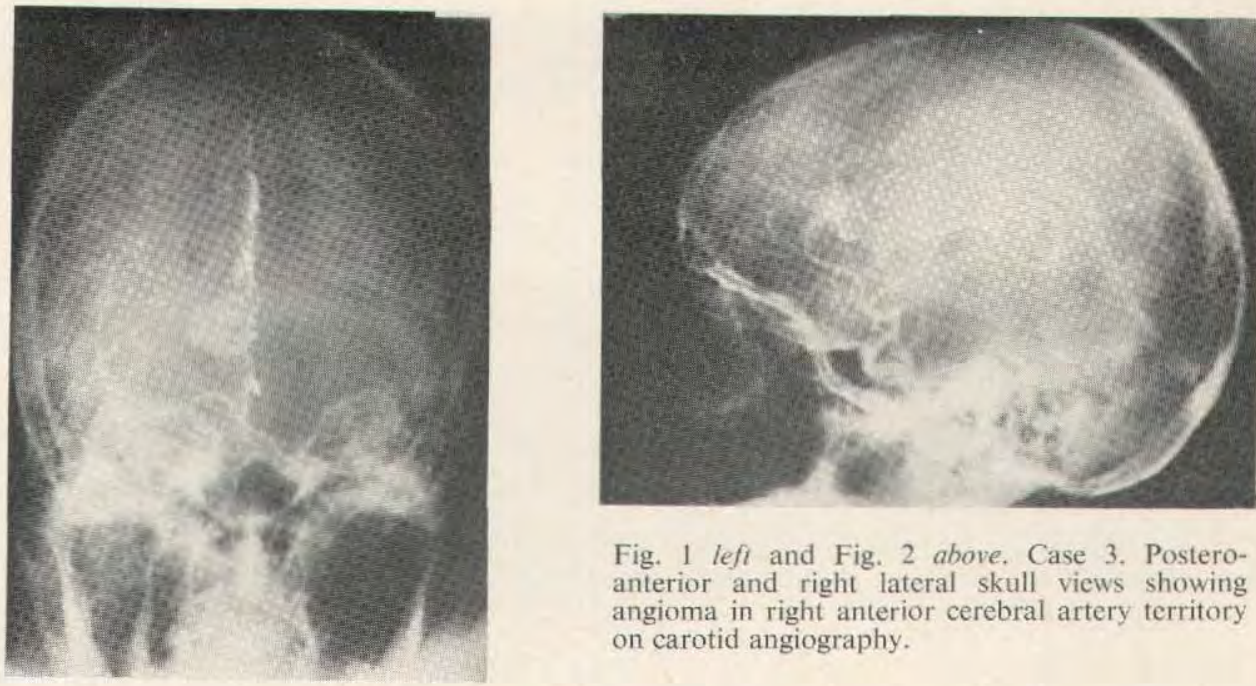

Fig. 1 left and Fig. 2 above. Case 3. Posteroanterior and right lateral skull views showing angioma in right anterior cerebral artery territory on carotid angiography.

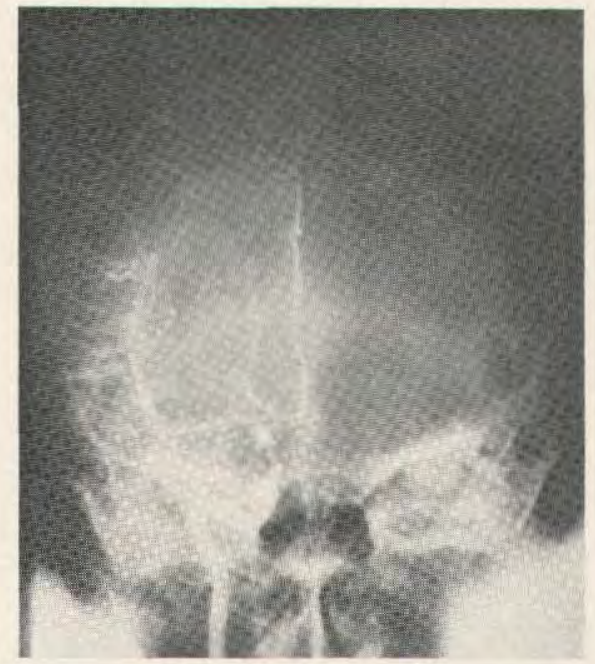

Figs. 3 and 4. Case 4. Postero-anterior and right lateral skull views showing right posterior communicating ancurysm on carotid angiography.

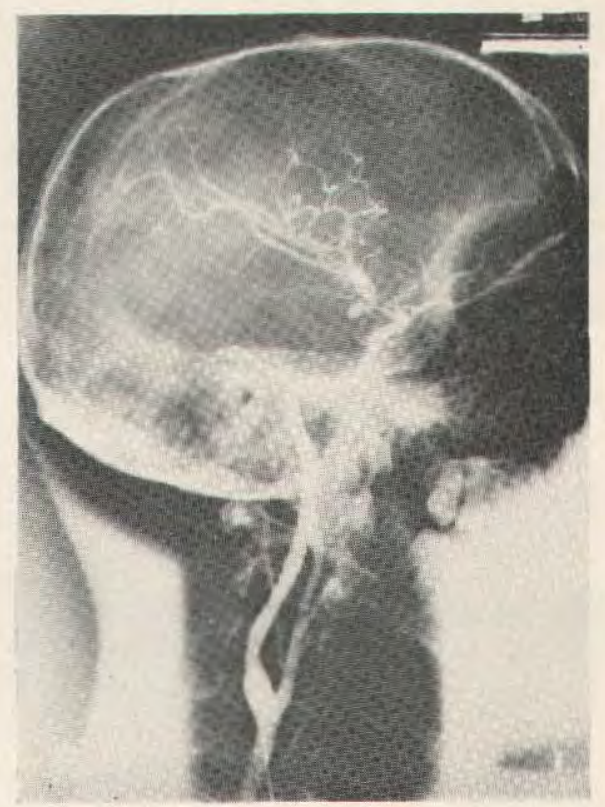

He remained fully conscious throughout his stay in hospital but on Day 8 he developed a partial right sided ptosis which became a complete right sided third cranial nerve palsy by Day 10 when he was seen at the Brooke Hospital, Woolwich, after evacuation from Germany.

Angiography showed an aneurysm at the junction of the right internal carotoid artery with the right posterior communicating artery (Figs 3 and 4). Thrombosis of this 
aneurysm was encouraged by the technique of gradual closure of the right common carotid artery, using a loop (Gibbs 1965). He made an uneventful recovery; with return of function of the right eye.

\section{Patient 5}

A 26 year old married soldier who had become involved in a fight whilst drunk at a party. He sustained one or two blows to his head and neck but subsequently left the party. Later that night he was found to be slowly lapsing into unconsciousness; and on arrival at hospital he was semi-comatose. He had a left sided subconjunctival haemorrhage, fundal haemorrhages and papilloedema, but skull X-ray revealed no fracture. Blood pressure was $140 / 80$. The cerebrospinal fluid contained 14,000 RBCs per $\mathrm{mm}^{3}$ with a protein content of $2,260 \mathrm{mg} / 100 \mathrm{ml}$.

It was soon obvious that his coma was deepening, and so, still on Day 1, he was transferred to the nearest German Neuro-Surgical Unit. Angiography revealed no intra-cranial aneurysm. He was beginning to lighten on Day 4, but on Day 7 he suddenly had a profuse haematemesis. Clinically he had also perforated his stomach, and he died later that day.

Post mortem examination showed profuse subarachnoid haemorrhage at the base of the brain, but the exact site of rupture could not be found: He also had gastric ulcers which had perforated and bled. The upper cervical spine was not examined for fractures.

\section{Patient 6}

A 9 month old female child who had allegedly fallen out of a pram 3 days before admission and out of a pushchair 2 days later.

She was admitted because of drowsiness and vomiting. There was bruising on the left side of her face. Ill-treatment was suspected but denied. Skull X-ray was normal. After 36 hours she developed generalised convulsions and held her head to the left. The muscle tone and tendon reflexes were increased on the left side and her pupils were sluggish in reaction and dilated. Fortunately she began to improve but neck stiffness, increased irritability and a mild pyrexia appeared. A careful lumbar puncture showed xanthochromic fluid with 30,000 RBCs per $\mathrm{mm}^{3}$ and a protein content of $30 \mathrm{mg} / 100 \mathrm{ml}$. The child made an uneventful recovery - a diagnosis of traumatic subarachnoid harmorrhage was made, and no further investigation was considered necessary.

\section{Patient 7}

A 42 year old housewife woke up one morning with a severe frontal headache, and later noticed paraesthesiae in the left leg and flashing lights in front of her eyes. She momentarily lost consciousness on her way to the toilet and vomited on her way into hospital.

She was found to be fully conscious but distressed. There was slight disorientation of thought and minimal neck stiffness. Her B.P. was 130/80. The cerebrospinal fluid was filled with blood-3,500,000 RBC's per $\mathrm{mm}^{3}$. Her condition remained static until Day 4 when the headache began to worsen, and the optic disc edge had become blurred. She was casevacuated to the Brooke Hospital on Day 6.

During the next 24 hours she began to deteriorate - a partial right sided third nerve paresis developed, and she became drowsy. Angiography showed a right sided posterior 
communicating aneurysm, which at craniotomy soon afterwards was found to be bleeding again. She has however, not fully recovered and will be left with considerable neurological deficit.

\section{Patient 8}

A 26 year old Sergeant who was admitted semi-comatose and unable to give a history. Apparently he had been complaining of headaches for three weeks involving particularly the region behind his left eye. A more severe headache occurred the day before admission, and he lapsed into a semi-conscious state overnight. He also showed signs of cerebral irritability, meningism and photophobia. His optic fundi were normal and B.P. 180/80. A clinical diagnosis of subarachnoid haemorrhage was supported by cerebrospinal fluid examination which was xanthochromic, contained 120,000 RBCs per $\mathrm{mm}^{3}$ and had a protein content of $340 \mathrm{mg} / 100 \mathrm{ml}$. He remained in a steady state for 18 hours but then suddenly developed cardiac arrest. After several episodes of both cardiac and respiratory arrest he died.

Post mortem examination showed a heavy subarachnoid haemorrhage covering the base of the brain, and on further dissection an aneurysm was found immediately posterior to the junction of the left internal carotid artery with the left posterior communicating artery.

\section{Discussion}

The causes of subarachnoid haemorrhage can be conveniently divided into 3 groups:-

Group 1. Those of spontaneous origin.

Group 2. Those of traumatic origin, and Group 3. Those arising as extension from intra-cerebral. or intra-cerebellar haemorrhage.

Group 3 may be considered separately from Groups 1 and 2, even though the haemorrhage arises either spontaneously or as a result of trauma. A different process is involved, where the primary haemorrhage is intra-cerebral (or intra-cerebellar), and only secondarily is there subarachnoid extension of the blood.

The presentation of such cases is usually dominated by the signs and symptoms of severe brain damage. The exception is the cerebral angioma, which, although strictly intra-cerebral, bleeds predominantly into the subarachnoid space. The clinical picture is therefore similar to that produced by a ruptured 'berry' aneurysm, and indeed, the diagnosis is not made until angiography. Hence Case 3, which concerned a cerebral angioma, and presented as a spontaneous subarachnoid haemorrhage is included in Group 1.

As a result of this inclusion, cases in the present series fall into Groups 1 and 2 only.

\section{Group 1}

Spontaneous subarachnoid haemorrhage most commonly arises from rupture of one or more 'berry ' aneurysms and cerebral angiography has demonstrated such aneurysms in 60 per cent of patients with spontaneous SAH selected for this procedure (Richardson 1973). 
Angiomatous malformation of cerebral vessels-cerebral angioma-can be found in 5 per cent of cases on angiography, and another 20 per cent have a primary cerebral or cerebellar origin for their haemorrhage. In the remaining 15 per cent, no lesion can be found, although the majority of these patients have aneurysms not demonstrable at the time. This group has a more favourable prognosis as will be discussed later.

There are other causes of spontaneous SAH which amount to less than 3 per cent of the total. The bleeding in these patients may arise from rupture of mycotic aneurysms, from rupture around atheromatous plaques, from cerebral tumours, as a result of bleeding diatheses, or other rarer causes.

To enable management of the individual case, some facts and figures about the natural history of 'berry' aneurysms should be borne in mind. Rupture of such aneurysms is responsible for a 50 per cent mortality, during the first six months, of those patients not subjected to surgery (Richardson 1969). Only 30 to 35 per cent die as a result of the initial 'bleed'. The other 10 to 15 per cent succumb from a ' rebleed', which usually occurs within 3 to 11 days of the first ' bleed ' (Gautier-Smith 1973), particularly from the 6th day onwards (Richardson 1973). Active surgical management, which includes cerebral angiography and subsequent surgery, is therefore primarily directed against this 10 to 15 per cent. Surgery, however, is rarely contemplated for those patients rendered unconscious by the initial episode and remaining comatose. As a group they are better treated conservatively (Richardson 1969).

Cerebral angiomata behave differently. They are found in only 5 per cent of all patients with spontaneous SAH, have a better immediate prognosis-12 per cent mortality at the end of the first week (Gautier-Smith 1973) and ' rebleed' in only 20 per cent of cases, even when considered over a number of years (Richardson 1969).

Surgery still offers the best prognosis in suitable cases, but by comparison with haemorrhage from ' berry' aneurysms, conservative management may be the treatment of choice, especially for lesions that are surgically less easily accessible.

Cerebral angiography is an essential investigation prior to surgery. Ninety-five per cent of aneurysms are found in that part of the circle of Willis supplied by the internal carotid arteries, and many centres used to perform bilateral carotid angiography without proceeding to investigate the vertebral arteries, although all four arteries should be examined for completeness. Angiography is not necessarily performed as an emergency procedure because, firstly, cerebral arterial spasm, secondary to the haemorrhage, often prevents adequate filling of the vessels, thereby producing false negative results, and secondly, angiography itself tends to induce arterial spasm, which may aggravate the patient's condition. It is best considered as an elective procedure on all patients, except those deeply unconscious, from the third day onwards. As rebleeding is a threat particularly from the sixth day, then this investigation with appropriate surgery should be performed between the third and fifth days.

Emergency carotid angiography is usually only considered for the patient who is initially conscious and in good condition, but who can be seen to be lapsing into unconsciousness because of the bleeding. Other conditions such as poor ventilation and dehydration must be excluded as causes of his deterioration, and if these are excluded emergency surgery offers his only hope of survival, albeit forlorn (Richardson 1973). 
However, cerebral angiography fails to demonstrate the source of bleeding in 15 per cent of patients. Several reasons have been put forward as an explanation for this. The technique itself may be faulty or the aneurysm inaccessible to the dye. There may be no filling of the aneurysm due to clotting in the sac, or the aneurysm may have been destroyed by the bleed. Whatever the explanation, it is known that such patients have, fortunately, a much better prognosis than those in whom a specific lesion is found.

It is of interest to note that 15 per cent of the patients submitted to carotid angiography for SAH have multiple aneurysms, and 15 per cent of the general population have demonstrable aneurysms at post mortem examinations.

\section{Management of individual cases of spontaneous $S A H$}

The patient is first brought to the nearest hospital, where the clinical diagnosis must be substantiated as soon as possible, and certainly before Day 5 , by examination of the cerebro-spinal fluid. If red blood cells are found in all specimens; with or without xanthochromia, the diagnosis of SAH is made, but its severity and the prognosis for the individual patient cannot be determined by a quantitative correlation with the number of red blood cells or the amount of protein in the fluid.

All patients not unconscious should then be transferred to the nearest appropriate Neuro-Surgical Unit, as soon as they are considered fit for travel. This usually when they have reached a "steady state".

In a British Military Hospital in the United Kingdom, this transfer may be conducted within the first 24 to 48 hours of admission. In Germany patients are casevacuated to the United Kingdom - this entails travel by air. They are not considered to be at additional risk whilst being flown, but the extra distance involved in travelling, organisation of aircraft and inclemency of weather may delay transfer for a further 24 hours. Retention in the hospitals of both countries should not be reasonably entertained after Day 5, if there is to be the maximum saving of patients from rebleeding.

Of the two patients in the series evacuated to the United Kingdom and subsequently found to have aneurysms, rebleeding occurred on Day 8 (Patient 4), and as early as Day 4 (Patient 7). In retrospect, it would have been wiser to have evacuated them sooner.

Once at the Neuro-Surgical Unit, cerebral angiography is performed as an elective procedure, except on those patients deeply unconscious, and surgery may follow as a result. A complete review of surgical indications and procedures is not intended here, but it is interesting to know that of the 90 per cent of aneurysms arising in internal carotid artery 'territory', about one third arise from the bifurcation of the main artery and the posterior communicating artery, another third at the junction of the anterior cerebral artery and the anterior communicating artery and a quarter from the middle cerebral artery (Richardson 1969). Posterior communicating aneurysms are particularly suitable for surgery, there being in one series a mortality, at the end of 6 weeks, of 10 per cent compared with 35 per cent in the patients treated conservatively (McKissock, Richardson and Walsh 1960), A less dramatic difference occurs in anterior communicating aneurysms, where the decision to operate is less easily reached. The choice of surgery, which lies usually between proximal artery ligation (or torsion) and direct attack on the aneurysmal sac, depends on many factors, such as the accessibility and site of the 
aneurysm, the presence of multiple aneurysms - which if on one side may indicate common carotid artery occlusion-and the general condition of the patient.

Neuro-Surgical Units also differ one from another. For instance common carotid artery occlusion by a technique of gradual torsion was introduced by Gibbs (1965) at the Brooke General Hospital, London, to which many British Army patients are sent. He prefers this to carotid artery ligation in that the threat of hemiplegia can be more easily reversed.

Emergency surgery may have to be considered even at the referring hospital if the patient is found to be losing consciousness, and may include paroximal artery ligation (or torsion), evacuation of haematoma and direct attack on the aneurysm.

The practice of conservative treatment for all cases, consisting essentially of bed rest and general measures, no longer has many advocates, although each case must be judged on its merits. But the technique of non-surgical intervention plus hypotensive therapy has given results comparable to surgery in some centres (Slossberg 1973) and cannot be lightly dismissed.

\section{Group 2}

Traumatic subarachnoid haemorrhage is probably under-diagnosed. Its presence is appreciated in some head injuries, when it occurs together with extradural and subdural intra-cerebral haemorrhage. Its recognition in such cases rarely alters management, but it may also occur ostensibly alone in minor or major injuries, with or without skull fracture. Patient 5 in this series undoubtedly had trauma to his head, but no skull fracture was found and at post mortem examination no obvious aneurysm could be found. The circumstances of his haemorrhage also underline the important part that alcohol seems to play in such patients. Simonsen (1967), found that of 430 cases of SAH, seventy-five (17. per cent) were due to trauma and of these, sixty-five ( 87 per cent) patients were under the unfluence of alcohol when haemorrhage occurred. He also noted that the vertebro-basilar arterial system was involved in the majority of cases, often with blows incurred at the level of the base of the skull. Cameron and Mant (1970) describe 4 cases of traumatic SAH and also stress the importance of alcoholism and blows directed to the side of the neck.

The prognosis for patients with traumatic SAH depends on the extent of the original trauma, and it is not possible to quote statistical probabilities. The management of these patients must also differ from those having a spontaneous bleed early evacuation to a Neuro-Surgical Unit is not necessarily the primary aim. However it is possible that the trauma could cause a rupture of a ' berry ' aneurysm, in which case early surgery would benefit the patient just as much as if the haemorrhage had been spontaneous.

\section{Conclusion}

As a result of the experience of managing 8 patients with subarachnoid haemorrhage, lessons have been learnt, and it is not unreasonable to suggest guide-lines for management of future cases.

Subarachnoid haemorrhage is an emergency whatever the cause but the mortality and morbidity of patients with 'berry' aneurysms can be considerably reduced by prompt diagnosis and early evacuation to a Neuro-Surgical Unit where specific investi- 
gations can be performed and surgery planned. In the meantime their general condition may demand correction of fluid and electrolyte imbalance, maintenance of airway, treatment of respiratory infection and other measures.

The comatose patient is, unfortunately, rarely worth evacuating. However, patients deteriorating quickly may require investigation and surgery within 24 hours, and in Germany, this may mean transfer to the nearest German Neuro-Surgical Centre.

Traumatic subarachnoid haemorrhage has been an unfashionable diagnosis in the past and is still probably under-diagnosed. It is frequently associated with alcoholic intoxication, and extreme care has to be taken in the examination of such patients, as not only are the consequences of the condition so unexpectedly serious for the patient after what is frequently minor trauma, but also the case is often later a subject for litigation in the courts:

\section{ACKNOWLEDGEMENTS}

I would like to pay tribute to the Royal Air Force for their efficiency and extreme co-operation in evacuating casualties from Germany, often at very short notice. I would also like to thank the staff at the Brooke Hospital, Woolwich, for their willingness to take our patients, and to Mr. J. R. Gibbs and Mr. A. A. G. Thompson in providing material for the preparation of this article. Lieutenant-Colonel D. Roberts, R.A.M.C., has made helpful suggestions in the preparation of the manuscript; and Frau Schreiber has patiently given considerable secretarial help.

\section{REFERENCES}

Cameron, J. M. and Mant, A. K. (1972). Med. Sci. Law 12, 66.

GAUTIER-SMith, P. C. (1973). J. roy. Coll. Phychs Lond, 7, 238

GiBBs, J, R. (1965). Brit. J. Surg. 52, 947.

McKissock, W., Richardson, A. E. and Walsh, L. (1960). Lancet i, 1203.

RICHARDSON, A. (1969). Brit. med. $\dot{J}$. iv, 89.

Rchardson, A. (1973). J. roy. Coll. Phyens Lond. 7, 245.

SiMONSEN, J. (1967). J. forens. Med. 14, 146.

Slossberg, P. (1973). N.Y. St. J. Med. 73, 679.

\section{Assurance Cover for Ulster at no Extra Cost}

Servicemen and Women in Northern Ireland, or about to be sent there, can obtain life assurance at no extra cost if they get their policy through Naafi.

Until now, Service people stationed in Northern Ireland have had to pay an extra premium on their life assurance or endowment policies. "Most companies charged the extra " said a spokesman for Naafi "some demanded as much as 50p per $£ 100$ throughout the whole term of the policy, not just while the soldier was in Ulster. This always struck us as unfair, so we are pleased that Naafi has managed to negotiate with two first class Life Offices for our customers to obtain cover, without paying an additional premium, for assurances maturing on the 66th birthday or earlier, up to the sum assured of $£ 10,000$ " .

Some Servicemen, such as nuclear submariners, aircraft pilots and bomb disposal crews, may still have to pay an extra premium wherever they servé. 